\title{
Diet quality of young children who received nutrition education promoting lower dietary fat†
}

\author{
Lori Beth Dixon ${ }^{1, *}$, Andrew M Tershakovec ${ }^{2}$, Jeannie McKenzie ${ }^{3}$ and Barbara Shannon ${ }^{3}$ \\ 'Division of Cancer Prevention, National Cancer Institute, Bethesda, MD 20892, USA: ${ }^{2}$ Division of \\ Gastroenterology and Nutrition, The Children's Hospital of Philadelphia, Philadelphia, PA 19104, USA: \\ ${ }^{3}$ Department of Nutrition, Pennsylvania State University, University Park PA 16802, USA
}

Submitted 7 September 1999: Accepted 30 March 2000

\begin{abstract}
Objective: To evaluate the impact of nutrition education promoting lower dietary fat on the overall diet quality in children using a multidimensional index that measures nutrient and food intakes in relation to US dietary recommendations.

Design: Prospective cohort study with two intervention and two control groups. Children with elevated low density lipoprotein (LDL) cholesterol were randomized to one of two intervention groups or an at-risk control group. The intervention children received either the parent-child autotutorial (PCAT) programme, a 10-week homebased self-instruction nutrition education programme, or nutrition counselling from a registered dietitian. Children with non-elevated plasma cholesterol formed the not-atrisk control group. Dietary and blood data were collected at baseline and at 3 months. Setting: Paediatric practices in suburbs north of Philadelphia, PA.

Subjects: Two hundred and twenty-seven 4-10-year-old children with elevated LDL cholesterol between the 80th and 98th percentiles, and 76 age- and gender-matched children with non-elevated plasma cholesterol, were studied.

Results: Children who received PCAT or counselling significantly improved their overall diet quality ( -0.6 and -0.4 change in diet quality index (DQI) scores) compared with at-risk control children. Children who received either form of nutrition education were more likely to meet the recommendations for three components of the DQI (total fat, saturated fat, sodium) (OR $>1.7)$, but did not improve their intakes of three components of the DQI (vegetables and fruits, complex carbohydrates, calcium) at 3 months.

Conclusions: Nutrition education promoting lower dietary fat improved children's overall diet quality. However, several dietary behaviours important for long-term health remained unchanged.
\end{abstract}

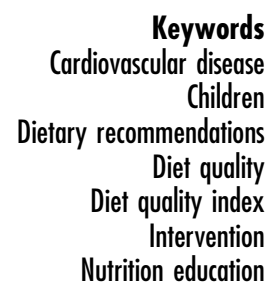

Nutrition research to reduce the risk of chronic disease has primarily focused on relationships between nutrients and levels of risk factors (e.g. dietary fat and plasma cholesterol). In response, many nutrition education interventions have targeted specific nutrients (e.g. dietary fat) but failed to emphasize other dietary behaviours (e.g. increasing vegetables and fruits) necessary to improve overall diet quality. As a result, certain aspects of participants' diets may improve from this approach, while other non-targeted aspects of their diets may not improve or may worsen. This is a concern, as overall diet quality, not individual nutrients or foods, is paramount for long-term health ${ }^{1-3}$.

Multidimensional indexes have been developed to evaluate overall diet quality ${ }^{4}$. These multidimensional indexes have been more strongly related to mortality and

†This paper was prepared in a personal capacity and does not necessarily represent the position of the NCI, nor does it construe endorsement of the publication by the NCI. risk of disease than measures of individual nutrients or foods ${ }^{4}$. One index, the DQI, was developed from eight diet and health recommendations issued by the National Academy of Sciences in 1989 for all persons aged 2 and older $^{5}$. This index was used to evaluate change in overall diet quality of adults across a series of cross-sectional surveys ${ }^{6}$. A similar index was used to evaluate overall diet quality in a nationally representative sample of children ${ }^{7}$. We hypothesized that the DQI would also be useful in evaluating change in overall diet quality resulting from nutrition education intervention. Such research is especially timely in children, as the prevalence of overweight children has doubled ${ }^{8}$, and current nutrition education interventions in children ${ }^{9-11}$ to reduce the prevalence of obesity and associated cardiovascular disease risk factors have focused on single nutrients, specifically dietary fat, but have not emphasized other dietary behaviours.

In the Children's Health Project, 4-10-year-old children received nutrition education promoting lower dietary fat 
to reduce their elevated LDL cholesterol levels ${ }^{12}$. This study provided an opportunity to evaluate the effect of this approach on change in the overall diet quality, as measured by change in DQI scores, of young children. A second objective was to determine how our nutrition education programme affected the likelihood of children meeting each dietary recommendation included in the DQI. We also compared children's change in the DQI with change in energy and other nutrients not included in the DQI. A final objective was to determine whether children's change in DQI corresponded to change in their plasma lipids or change in their body size.

\section{Methods}

\section{The Children's Health Project}

The Children's Health Project is a prospective cohort study, comprised of 303 children aged 4-10 years who were recruited from paediatric practices in suburbs north of Philadelphia, beginning in 1991. Children with elevated LDL cholesterol (between the 80th and 98th percentiles) were randomized into one of two nutrition education groups or into an at-risk control group. A fourth group of age-matched children with non-elevated total cholesterol served as a second control group. This not-at-risk control group was included to evaluate whether any factors external to the study (e.g. information about diet and heart disease in the media) would differentially affect the diets and serum lipids of children with and without elevated LDL cholesterol who did not receive nutrition education.

Children in the PCAT programme received a homebased self-instruction programme comprised of 10 'talking book' lessons about healthy eating patterns for children with an accompanying audiotape, picture booklet, paper and pencil, activities workbook and parent manual. As previously described ${ }^{13}$, commonly consumed foods were designated as 'heart smart' or 'not heart smart' based on their content of total and saturated fat using criteria developed by the Minnesota Heart Health Program. Each lesson and activity encouraged children to eat more 'heart smart' foods. For example, children were encouraged to drink skim milk instead of whole milk. Children were encouraged to eat vegetables but not vegetables that were fried. Children in the counselling programme received 1 hour of face-to-face nutrition counselling from a registered dietitian who provided materials that complied with the National Cholesterol Education Program (NCEP) Expert Panel on Blood Cholesterol Levels in Children and Adolescents ${ }^{14}$. The dietary goals of both intervention programmes were to meet the NCEP step 1 dietary guidelines $(\leqslant 30 \%$ calories from fat, $<10 \%$ calories from saturated fat, $<300 \mathrm{mg}$ cholesterol day ${ }^{-1}$ ). Neither control group received nutrition education; both control groups were instructed to maintain typical eating habits.

Before and after the 3-month intervention, three 24hour dietary recalls were conducted with each child and primary caretaker by telephone interview using the University of Minnesota's computer-assisted Nutrition Data System (NDS) ${ }^{15}$. Two fasting plasma samples for total cholesterol, triglycerides and high density lipoprotein (HDL) cholesterol assessment were also collected from 198 hypercholesterolaemic children at baseline and at 3 months. The children's LDL cholesterol concentrations were then calculated according to the Friedewald equation ${ }^{16}$. Blood was not drawn from the normocholesterolaemic children after an initial plasma cholesterol screening test. Children's weights and heights were measured twice by trained anthropometrists at both time periods. Further detail about the Children's Health Project is provided elsewhere ${ }^{12,13}$.

\section{Calculation of DQI scores}

The DQI is comprised of six nutrients and two food groups associated with eight diet and health recommendations (see Table 2). Using this index, a DQI score was determined for each child at baseline and at 3 months. Mean nutrient intakes of total fat, saturated fat, cholesterol, protein, sodium and calcium were calculated by the NDS software from the children's 24-hour dietary recalls at both time periods. Unfortunately, the version of the NDS software used in this study did not calculate mean servings of vegetables and fruits or complex carbohydrates. We wrote a program using Statistical Analysis System (SAS) software that calculated servings of food groups from dietary data generated by the NDS ${ }^{17}$. We assigned each food from the children's 24-hour recalls to one of 10 main food groups, including vegetables, fruits and complex carbohydrates. We also converted the gram amounts of each food, provided by the NDS, to servings (e.g. $26 \mathrm{~g}=$ 1 slice of bread $=1$ serving) and quantified the number of servings from each food group for each child. The NDS software provided gram amounts of component foods of mixed dishes (e.g. apples in apple pie), allowing us to include those foods in our calculation of servings of their respective food groups (e.g. fruits).

For each component of the DQI, children received a score of 0 if their intake met the respective diet and health recommendation, a score of 1 if their intake was fair compared with the recommendation, or a score of 2 if their intake was poor compared with the recommendation. The definitions of the score categories for each recommendation were based on the original $\mathrm{DQI}^{5}$, with the exception of calcium where we used the 1998 Dietary Reference Intake (DRI) ${ }^{18}$ in place of the 1989 Recommended Dietary Allowance $(\mathrm{RDA})^{19}$. After summing across all eight recommendations, children's DQI scores ranged from 0 to 16 with lower scores showing diets more in accordance with the recommendations.

\section{Statistical analyses}

Baseline and change (adjusted for baseline) in DQI scores were compared among the four study groups using 
general linear model analysis of variance with the at-risk control children as the reference group. Within each study group, percentages of children who scored a 0,1 or 2 were determined for each of the eight diet and health recommendations at baseline and follow-up. Percentages of children within each study group who met each dietary recommendation at both time periods or at 3 months only (i.e. those who maintained or improved their diets from baseline) were compared with children who did not meet the recommendations at 3 months (i.e. those whose diets worsened or failed to improve from baseline) by chi-square analysis. We also conducted logistic regression analyses to determine whether children within each study group were more likely to meet each dietary recommendation at 3 months relative to baseline. The at-risk control children served as the comparison group. These analyses were repeated by combining all children who received nutrition education (PCAT and counselling) and comparing them with all control children (at-risk and not-at-risk). Odds ratios generated from the logistic regressions were adjusted for baseline intakes of the respective nutrient or food.

Pearson correlation coefficients were calculated between the children's change in DQI and their change in its components, energy and other nutrients important to children's health ${ }^{20}$. Pearson correlation coefficients were also calculated between the children's change in DQI and their change in average plasma lipids, and between the children's change in DQI and their change in average weight, height and body mass index (BMI). All analyses used PC-SAS version $6.12^{21}$.

\section{Results}

Baseline DQI scores did not differ among the four study groups of children (Table 1). At 3 months, children who received nutrition education significantly reduced their average DQI scores in the direction of a more healthy diet compared with at-risk control children. Improvement in overall diet quality was most notable among children who received the 10-week PCAT programme.

At baseline, approximately half of all children met the guidelines for total fat and one-third of all children met the guidelines for saturated fat, with significantly higher percentages of children who received nutrition education meeting those recommendations at 3 months relative to control children (Table 2). Regardless of study group, most children met the dietary cholesterol recommendation at baseline and maintained this after intervention. In all study groups, the percentages of children who met the recommendations for vegetables and fruits and for calcium intake changed very little at 3 months relative to baseline. Although some children who received nutrition education did increase their servings of grains, less than half met the recommendation of six or more servings at 3 months. In contrast, more than half of the children who received nutrition education met the recommendations for protein and sodium after intervention.

Compared with the at-risk control children or both groups of control children, children who received nutrition education were significantly more likely to meet the dietary recommendations for total fat, saturated fat and sodium at 3 months (Table 3). Although not statistically significant, children who received nutrition education were less likely to meet the recommendations for vegetables and fruits, complex carbohydrates and calcium than control children.

Among all 303 children, change in DQI was significantly correlated with change in all components of the index $(r>0.44$ for fats, $r=-0.38$ for vegetables and fruits, $r=$ -0.15 for complex carbohydrates, $r=0.22$ for protein, $r=$ 0.25 for sodium), except calcium $(r<0.08)$. Change in DQI was also significantly correlated with change in energy $(r=0.12)$, dietary fibre $(r=-0.14)$, vitamin C ( $r=$ $-0.19)$, iron $(r=-0.11)$ and zinc $(r=0.13)$. Change in DQI did not correlate with change in vitamins $\mathrm{A}, \mathrm{B}_{6}, \mathrm{~B}_{12}$, D and $\mathrm{E}$, folate or magnesium $(r<0.11)$. Among the 198 hypercholesterolaemic children whose plasma lipids were measured in this study, change in DQI did not correlate with change in total, LDL or HDL cholesterol or plasma triglycerides $(r<0.11)$. Change in DQI also did not correlate with change in weight, height or BMI $(r<0.1)$.

\section{Discussion}

In our study, children who received nutrition education improved their overall diet quality compared with control

Table 1 Least square means and standard errors of baseline, 3 months, and change (adjusted for baseline) in average diet quality index (DQI) scores* in four Children's Health Project study groups

\begin{tabular}{lcccc}
\hline Time period & $\begin{array}{c}\text { PCAT } \\
(N=71)\end{array}$ & $\begin{array}{c}\text { Counselling } \\
(N=77)\end{array}$ & $\begin{array}{c}\text { At-risk control } \\
(N=79)\end{array}$ & $\begin{array}{c}\text { Not-at-risk control } \\
(N=76)\end{array}$ \\
\hline Baseline & $5.6 \pm 0.2$ & $6.0 \pm 0.2$ & $5.7 \pm 0.2$ & $5.8 \pm 0.2$ \\
3 months & $5.2 \pm 0.2$ & $5.5 \pm 0.2$ & $6.0 \pm 0.2$ & $5.7 \pm 0.2$ \\
Change & $-0.6 \pm 0.2 \dagger$ & $-0.4 \pm 0.2 \ddagger$ & $0.3 \pm 0.2 \dagger \ddagger$ & $-0.1 \pm 0.2$ \\
\hline
\end{tabular}

PCAT, parent-child autotutorial programme.

* Scores $(0,1,2)$ from each diet and health recommendation were summed across all eight diet and health recommendations to calculate DQI scores for each child within each study group.

$\dagger P<0.006$ (PCAT vs. at-risk controls).

$\ddagger P<0.02$ (counselling vs. at-risk controls). 
Table 2 Percentages of children within each Children's Health Project study group who scored 0,1 or 2 for each diet and health recommendation at baseline (B) and 3 months (3M)

\begin{tabular}{|c|c|c|c|c|c|c|c|c|c|c|}
\hline \multirow[b]{2}{*}{ Diet and health recommendation } & \multirow[b]{2}{*}{ Score $^{*}$} & \multirow[b]{2}{*}{ Intake } & \multicolumn{2}{|c|}{ PCAT } & \multicolumn{2}{|c|}{ Counselling } & \multicolumn{2}{|c|}{$\begin{array}{l}\text { At-risk } \\
\text { control }\end{array}$} & \multicolumn{2}{|c|}{$\begin{array}{l}\text { Not-at-risk } \\
\text { control }\end{array}$} \\
\hline & & & $\begin{array}{l}\mathrm{B} \\
(\%)\end{array}$ & $\begin{array}{l}3 \mathrm{M} \\
(\%)\end{array}$ & $\begin{array}{l}\mathrm{B} \\
(\%)\end{array}$ & $\begin{array}{l}3 \mathrm{M} \\
(\%)\end{array}$ & $\begin{array}{l}B \\
(\%)\end{array}$ & $\begin{array}{l}3 \mathrm{M} \\
(\%)\end{array}$ & $\begin{array}{l}\mathrm{B} \\
(\%)\end{array}$ & $\begin{array}{l}3 \mathrm{M} \\
(\%)\end{array}$ \\
\hline $\begin{array}{l}\text { Reduce total fat intake to } \\
\leqslant 30 \% \text { of energy }\end{array}$ & $\begin{array}{l}0 \\
1 \\
2\end{array}$ & $\begin{array}{r}\leqslant 30 \% \\
30.1-40 \% \\
>40 \%\end{array}$ & $\begin{array}{r}60.6 \\
38.0 \\
1.4\end{array}$ & $\begin{array}{c}67.6 \dagger \\
32.4 \\
0.0\end{array}$ & $\begin{array}{r}53.2 \\
44.2 \\
2.6\end{array}$ & $\begin{array}{c}63.6+ \\
36.4 \\
0.0\end{array}$ & $\begin{array}{r}46.8 \\
50.6 \\
2.5\end{array}$ & $\begin{array}{l}45.6 \dagger \\
49.4 \\
5.1\end{array}$ & $\begin{array}{r}48.7 \\
51.3 \\
0.0\end{array}$ & $\begin{array}{c}56.6 \dagger \\
38.2 \\
5.3\end{array}$ \\
\hline $\begin{array}{l}\text { Reduce saturated fatty } \\
\text { acid intake to }<10 \% \\
\text { of energy }\end{array}$ & $\begin{array}{l}0 \\
1 \\
2\end{array}$ & $\begin{array}{r}<10 \% \\
10-13 \% \\
>13 \%\end{array}$ & $\begin{array}{l}39.4 \\
40.8 \\
19.7\end{array}$ & $\begin{array}{l}45.1 \dagger \\
42.2 \\
12.7\end{array}$ & $\begin{array}{l}33.8 \\
44.2 \\
22.1\end{array}$ & $\begin{array}{l}45.4 \dagger \\
41.6 \\
13.0\end{array}$ & $\begin{array}{l}29.1 \\
41.8 \\
29.1\end{array}$ & $\begin{array}{l}25.3 \dagger \\
53.2 \\
21.5\end{array}$ & $\begin{array}{l}30.3 \\
42.1 \\
27.6\end{array}$ & $\begin{array}{l}31.6 \dagger \\
47.4 \\
21.1\end{array}$ \\
\hline $\begin{array}{l}\text { Reduce cholesterol to } \\
<300 \mathrm{mg} \text { daily }\end{array}$ & $\begin{array}{l}0 \\
1 \\
2\end{array}$ & $\begin{array}{r}<300 \mathrm{mg} \\
300-400 \mathrm{mg} \\
>400 \mathrm{mg}\end{array}$ & $\begin{array}{r}97.2 \\
2.8 \\
0.0\end{array}$ & $\begin{array}{r}98.6 \\
1.4 \\
0.0\end{array}$ & $\begin{array}{r}92.2 \\
6.5 \\
1.3\end{array}$ & $\begin{array}{r}94.8 \\
5.2 \\
0.0\end{array}$ & $\begin{array}{r}94.9 \\
5.1 \\
0.0\end{array}$ & $\begin{array}{r}89.9 \\
6.3 \\
3.8\end{array}$ & $\begin{array}{r}88.2 \\
9.2 \\
2.6\end{array}$ & $\begin{array}{r}89.5 \\
7.9 \\
2.6\end{array}$ \\
\hline $\begin{array}{l}\text { Eat five or more servings } \\
\text { daily of a combination } \\
\text { of vegetables and fruits }\end{array}$ & $\begin{array}{l}0 \\
1 \\
2\end{array}$ & $\begin{array}{l}5+\text { svgs } \\
3-4 \text { svgs } \\
0-2 \text { svgs }\end{array}$ & $\begin{array}{l}12.7 \\
36.6 \\
50.7\end{array}$ & $\begin{array}{l}12.7 \\
23.9 \\
63.4\end{array}$ & $\begin{array}{l}13.0 \\
28.6 \\
58.4\end{array}$ & $\begin{array}{l}11.7 \\
23.4 \\
64.9\end{array}$ & $\begin{array}{l}29.1 \\
20.2 \\
50.6\end{array}$ & $\begin{array}{l}20.2 \\
32.9 \\
46.8\end{array}$ & $\begin{array}{l}22.4 \\
32.9 \\
44.7\end{array}$ & $\begin{array}{l}19.7 \\
30.3 \\
50.0\end{array}$ \\
\hline $\begin{array}{l}\text { Increase intake of starches } \\
\text { and other complex } \\
\text { carbohydrates by eating } \\
\text { six or more servings } \\
\text { daily of breads, cereal } \\
\text { and legumes }\end{array}$ & $\begin{array}{l}0 \\
1 \\
2\end{array}$ & $\begin{array}{l}6+\text { svgs } \\
4-5 \text { svgs } \\
0-3 \text { svgs }\end{array}$ & $\begin{array}{l}33.8 \\
46.5 \\
19.7\end{array}$ & $\begin{array}{l}40.8 \\
38.0 \\
21.1\end{array}$ & $\begin{array}{l}40.3 \\
28.6 \\
31.2\end{array}$ & $\begin{array}{l}33.8 \\
45.4 \\
20.8\end{array}$ & $\begin{array}{l}36.7 \\
43.0 \\
20.2\end{array}$ & $\begin{array}{l}46.8 \\
39.2 \\
13.9\end{array}$ & $\begin{array}{l}43.4 \\
42.1 \\
14.5\end{array}$ & $\begin{array}{l}54.0 \\
32.9 \\
13.2\end{array}$ \\
\hline $\begin{array}{l}\text { Maintain protein intake at } \\
\text { moderate levels (levels } \\
\text { lower than twice the RDA) }\end{array}$ & $\begin{array}{l}0 \\
1 \\
2\end{array}$ & $\begin{array}{r}\leqslant 200 \% \text { RDA } \\
200-250 \% \text { RDA } \\
>250 \% \text { RDA }\end{array}$ & $\begin{array}{r}47.9 \\
43.7 \\
8.4\end{array}$ & $\begin{array}{c}59.2 \dagger \\
36.6 \\
4.2\end{array}$ & $\begin{array}{l}37.7 \\
48.1 \\
14.3\end{array}$ & $\begin{array}{l}44.2 \dagger \\
45.4 \\
10.4\end{array}$ & $\begin{array}{l}43.0 \\
45.6 \\
11.4\end{array}$ & $\begin{array}{l}35.4 \dagger \\
43.0 \\
21.5\end{array}$ & $\begin{array}{l}30.3 \\
55.3 \\
14.5\end{array}$ & $\begin{array}{l}36.8 \dagger \\
43.4 \\
19.7\end{array}$ \\
\hline $\begin{array}{l}\text { Limit total daily intake of } \\
\text { sodium to } \leqslant 6 \mathrm{~g} \text { ( } 2400 \mathrm{mg} \text { ) }\end{array}$ & $\begin{array}{l}0 \\
1 \\
2\end{array}$ & $\begin{array}{r}\leqslant 2400 \mathrm{mg} \\
2400-3400 \mathrm{mg} \\
>3400 \mathrm{mg}\end{array}$ & $\begin{array}{r}67.6 \\
25.4 \\
7.0\end{array}$ & $\begin{array}{c}69.0 \dagger \\
26.8 \\
4.2\end{array}$ & $\begin{array}{l}59.7 \\
26.0 \\
14.3\end{array}$ & $\begin{array}{l}66.2 \dagger \\
28.6 \\
5.2\end{array}$ & $\begin{array}{l}58.2 \\
31.6 \\
10.1\end{array}$ & $\begin{array}{l}46.8 \dagger \\
43.0 \\
10.1\end{array}$ & $\begin{array}{l}47.4 \\
35.5 \\
17.1\end{array}$ & $\begin{array}{l}50.0 \dagger \\
32.9 \\
17.1\end{array}$ \\
\hline $\begin{array}{l}\text { Maintain adequate calcium } \\
\text { intake (approximately } \\
\text { DRI levels) }\end{array}$ & $\begin{array}{l}0 \\
1 \\
2\end{array}$ & $\begin{array}{r}\geqslant 100 \% \text { DRI } \\
67-100 \% \text { DRI } \\
<67 \% \text { DRI }\end{array}$ & $\begin{array}{l}28.2 \\
28.2 \\
43.7\end{array}$ & $\begin{array}{l}29.6 \\
36.6 \\
33.8\end{array}$ & $\begin{array}{l}35.1 \\
40.3 \\
24.7\end{array}$ & $\begin{array}{l}32.5 \\
42.9 \\
24.7\end{array}$ & $\begin{array}{l}39.2 \\
41.8 \\
19.0\end{array}$ & $\begin{array}{l}38.0 \\
34.2 \\
27.8\end{array}$ & $\begin{array}{l}46.1 \\
38.2 \\
15.8\end{array}$ & $\begin{array}{l}44.7 \\
34.2 \\
21.1\end{array}$ \\
\hline
\end{tabular}

DRI, dietary reference intake; PCAT, parent-child autotutorial programme; RDA, recommended daily allowance; svgs, servings.

* Score categories: $0=$ excellent diet; 1 = fair diet; $2=$ poor diet.

$\dagger P<0.05$ for chi-square analysis comparing the percentages of children who met each recommendation (i.e. score $=0$ ) at 3 months with those who did not meet the recommendation (i.e. score $=1$ or 2 ) at 3 months across the four study groups.

children. Among the eight components of the DQI, children who received nutrition education were more likely to meet the dietary fat recommendations at 3 months compared with control children. This was not surprising as our nutrition education programmes were based on the NCEP step 1 diet guidelines that emphasize reducing dietary fat ${ }^{14}$. Children who received nutrition education were also more likely to meet the sodium recommendation compared with control children. This also was not surprising because many higher fat foods (e.g. meat, full-fat dairy products) are higher in sodium. What was surprising, however, was that children who received nutrition education were less likely to meet the recommendations for vegetables and fruits, complex carbohydrates and calcium compared with control children. We believe this occurred because our nutrition

Table 3 Odds ratios* and 95\% confidence intervals of meeting each diet and health recommendation at 3 months by Children's Health Project study groups

\begin{tabular}{lccrr}
\hline Diet and health recommendation & PCAT† & Counsellingt & $\begin{array}{c}\text { Not-at-risk } \\
\text { control† }\end{array}$ & $\begin{array}{c}\text { Education vs. } \\
\text { controlł }\end{array}$ \\
\hline Total fat & $2.46(1.21,5.06)$ & $2.14(1.08,4.31)$ & $1.66(0.85,3.28)$ & $1.78(1.09,2.92)$ \\
Saturated fat & $2.51(1.20,5.35)$ & $2.64(1.28,5.56)$ & $1.64(0.77,3.53)$ & $2.01(1.21,3.38)$ \\
Cholesterol & - & - & - & - \\
Vegetables and fruits & $0.84(0.30,2.28)$ & $0.81(0.29,2.20)$ & $1.22(0.49,3.09)$ & $0.75(0.36,1.51)$ \\
Complex carbohydrates & $0.90(0.43,1.90)$ & $0.56(0.27,1.21)$ & $1.20(0.58,2.48)$ & $0.66(0.39,1.11)$ \\
Protein & $2.18(1.08,4.43)$ & $1.44(0.73,2.87)$ & $1.24(0.62,2.50)$ & $1.58(0.96,2.59)$ \\
Sodium & $2.06(0.98,4.39)$ & $2.48(1.19,5.30)$ & $1.36(0.66,2.80)$ & $1.96(1.16,3.36)$ \\
Calcium & $0.94(0.44,2.00)$ & $0.74(0.35,1.55)$ & $1.07(0.53,2.18)$ & $0.80(0.47,1.36)$ \\
\hline
\end{tabular}

* Odds ratios were adjusted for baseline intakes of the respective nutrient or food. Odds ratios for cholesterol are missing due to very small counts in cells. $\dagger$ Each group was compared with the at-risk control children.

$\ddagger$ Children who received nutrition education (PCAT and counselling) were compared with control (at-risk and not-at-risk) children. 
education programmes encouraged lower fat choices in these types of foods but did not emphasize increasing their overall intake. The Child and Adolescent Trial for Cardiovascular Health, a school-based nutrition education intervention that emphasized lower fat foods, also reported that children did not increase their intake of vegetables and fruits ${ }^{22}$. Our findings support their conclusions that 'general messages are not likely to change specific non-targeted behaviors'.

In a previous analysis of the Children's Health Project ${ }^{12}$, children who received nutrition education significantly lowered their total and saturated fat intake and their plasma LDL cholesterol compared with the at-risk control children. However, in this study, children's change in DQI was not associated with change in plasma lipids. This was not surprising because the DQI includes components other than dietary fat that are not associated with plasma lipids. Children's change in DQI was also not associated with change in weight, height or BMI. This was not unexpected either because change in DQI was weakly correlated with change in energy intake. Although previous studies have reported associations of multidimensional indexes with risk factors of disease, unlike the DQI, those indexes were entirely food-based and the outcome variables were different than those measured in our study ${ }^{4}$. In addition, the time periods were longer than 3 months and the study populations were adults.

The small amount of change in DQI may also have prevented us from finding a statistically significant association with change in a biological parameter. Such a small change in DQI may have been partially due to our methods. For example, we grouped foods according to the NCEP guidelines and placed potatoes in the grain group. According to national data ${ }^{23}$, French fries accounted for approximately $25 \%$ of vegetable intake reported by children, which may explain why so few children met the recommended five servings of vegetables and fruits before or after intervention. It is possible that children who received nutrition education were more likely to replace French fries with other vegetables, but the DQI is not designed to capture this change. We also used the DRI ${ }^{18}$ to calculate score categories of calcium intake. The DRI is higher than the $1989 \mathrm{RDA}^{19}$ used in the original $\mathrm{DQI}^{5}$, making it more difficult for children to achieve that recommendation. Furthermore, our estimates of sodium intake did not include salt added at the table, which has been shown to contribute an additional $6 \%$ of sodium ${ }^{24}$. This may explain why approximately half of the children met the sodium recommendation before and after intervention.

Our findings, and those of others ${ }^{6,7}$, suggest that multidimensional indexes like the DQI are best used to identify dietary behaviours that need improvement. However, an index is only as good as the components included and, as mentioned previously, is sensitive to the methodology used to categorize those components. In children, other nutrients like iron are especially important and should be considered in the scoring of diet quality ${ }^{20}$. As in adults ${ }^{25}$, measures of dietary diversity and moderation may also be important contributors to diet quality in children. One important practical consideration, however, for calculating these indexes is whether the instrument used to assess dietary intake (e.g. 24-hour recalls, food frequency questionnaires) is linked to software that can calculate nutrient intakes, servings of food groups and measures like dietary diversity and moderation.

It is important to mention that our study subjects were predominantly white children from middle to upper income households in the northeast USA, which may limit our ability to generalize our findings to all children. Also, although we made a substantial effort to collect accurate dietary data ${ }^{26}$, any measure of diet has inherent limitations of accuracy due to reporting bias or measurement error. However, our findings were determined from multiple days of dietary data and were comparable to national data ${ }^{7,27,28}$.

\section{Conclusions}

Nutrition education that focuses on specific nutrients (e.g. dietary fat) may result in overlooking other important aspects of children's diets. To improve the overall impact of nutrition education, the goals of an intervention should include a broader range of dietary recommendations appropriate for children. The nutrition education programme should also link food-related behaviours where possible (e.g. lowering dietary fat by replacing higher fat foods with vegetables and fruits, and increasing dietary calcium by eating calcium-rich foods that are low in saturated fat).

\section{Acknowledgements}

The Children's Health Project was supported by grant HL43880-03 from the National Heart, Lung and Blood Institute, National Institutes of Health; a grant from the Howard Heinz Endowment; and a grant from the National Dairy Promotion and Research Board in conjunction with the National Dairy Council. Informed consent was obtained from the caretakers of all participants in accordance with the internal review board at the Children's Hospital of Philadelphia and the Office of Regulatory Compliance for the Protection of Human Subjects at the Pennsylvania State University. The authors greatly appreciate the insightful comments of Drs Christopher Gardner, Michaela Kiernan and Marilyn Winkleby on earlier drafts of the manuscript.

\section{References}

1 National Research Council. Diet and Health: Implications for Reducing Chronic Disease Risk. Report of the Committee on Diet and Health, Food and Nutrition Board, Commission on Life Sciences. Washington, DC: National Academy Press, 1989. 
2 US Department of Agriculture, US Department of Health and Human Services. Dietary Guidelines for Americans, 4th edn. Washington, DC: Government Printing Office, 1995.

3 US Department of Agriculture, Human Nutrition Information Service. The Food Guide Pyramid. Home and Garden Bulletin No. 252. Washington, DC: Government Printing Office, 1992.

4 Kant AK. Indexes of overall diet quality: a review. J. Am. Diet. Assoc. 1996; 96: 785-91.

5 Patterson RE, Haines PS, Popkin BM. Diet quality index: capturing a multidimensional behavior. J. Am. Diet. Assoc. 1994; 94: 57-64.

6 Popkin BM, Siega-Riz AM, Haines PS. A comparison of dietary trends among racial and socioeconomic groups in the United States. N. Engl. J. Med. 1996; 335: 716-20.

7 Lino M, Gerrior SA, Basiotis PP, Anand RS. Report Card on the Diet Quality of Children. Nutrition Insight 9. Washington, DC: USDA Center for Nutrition Policy and Promotion, 1998.

8 Troiano RP, Flegal KM. Overweight children and adolescents; description, epidemiology, and demographics. Pediatrics 1998; 101: 497-504.

9 Lytle LA, Stone EJ, Nichaman MZ, et al. Changes in nutrient intakes of elementary school children following a schoolbased intervention: results from the CATCH study. Prev. Med. 1996; 25: 465-77.

10 Snyder P, Anliker J, Cunningham-Sabo L, et al. The Pathways study: a model for lowering the fat in school meals. Am.J. Clin. Nutr. 1999; 69 (Suppl.): S810-15.

11 The Writing Group for the DISC Collaborative Research Group. Efficacy and safety of lowering dietary fat intake of fat and cholesterol in children with elevated low-density lipoprotein cholesterol. JAMA 1995; 273: 1429-35.

12 Shannon BM, Tershakovec AM, Martel JK, et al. Reduction of elevated LDL-cholesterol levels of 4- to 10-year-old children through home-based education. Pediatrics 1994; 94: 923-7.

13 Shannon BM, Greene G, Stallings V, et al. A dietary education program for hypercholesterolemic children and their parents. J. Am. Diet. Assoc. 1991; 91: 208-12.

14 National Cholesterol Education Program. Report of the Expert Panel on Blood Cholesterol Levels in Children and Adolescents. NIH Publication No. 91-2732. Bethesda, MD: US Department of Health and Human Services/PHS/NIH/ NHLBI, 1992.

15 Nutrition Coordinating Center. Minnesota Nutrition Data
System (NDS) Software. Food Database version 4A, Nutrient Database version 19. Minneapolis, MN: University of Minnesota, 1990

16 Friedewald WR, Levy RI, Fredrickson DS. Estimation of the concentration of low density lipoprotein cholesterol without the use of the preparative ultracentrifuge. Clin. Chem. 1972; 18: $499-502$

17 Dixon LB. Diets of Hypercholesterolemic Children and the Relationship of Diet and Familial Characteristics to Change in their Blood Lipids. Dissertation, Pennsylvania State University, Pennsylvania, 1994.

18 Yates AA, Schlicker SA, Suitor CW. Dietary reference intakes the new basis for recommendations for calcium and related nutrients, B vitamins, and choline. J. Am. Diet. Assoc. 1998; 98: 699-706.

19 Food and Nutrition Board. Recommended Dietary Allow ances, 10th edn. Washington, DC: National Academy Press, 1989.

20 McPherson RS, Montgomery DH, Nichaman MZ. Nutritional status of children: what do we know? J. Nutr. Educ. 1995; 27(5): 225-34

21 SAS Institute. SAS/STAT User's Guide, Version 6, 4th edn Cary, NC: Statistical Analysis System Institute, 1989.

22 Perry CL, Lytle LA, Feldman H, et al. Effects of the Child and Adolescent Trial for Cardiovascular Health (CATCH) on fruit and vegetable intake. J. Nutr. Educ. 1998; 30: 35460.

23 Krebs-Smith SM, Cook A, Subar AF, Cleveland L, Friday J, Kahle LL. Fruit and vegetable intakes of children and adolescents in the United States. Arch. Pediatr. Adolesc. Med. 1996; 150(1): 81-6.

24 Mattes RD, Donnelly D. Relative contributions of dietary sodium sources. J. Am. Coll. Nutr. 1991; 10(4): 383-93.

25 Haines PS, Siega-Riz AM, Popkin BM. The diet quality index revised: a measurement instrument for populations. J. Am. Diet. Assoc. 1999; 99: 697-704.

26 Derr JA, Mitchell DC, Brannon D, Smiciklas-Wright H, Dixon LB, Shannon BM. Time and cost analysis of a computerassisted telephone interview system to collect dietary recalls. Am. J. Epidemiol. 1992; 136: 1386-92.

27 Munoz KA, Krebs-Smith SM, Ballard-Barbash R, Cleveland LE. Food intakes of US children and adolescents compared with recommendations. Pediatrics 1997; 100: 323-9.

28 Munoz KA, Krebs-Smith SM, Ballard-Barbash R, Cleveland LE. Errors in food intake article. Pediatrics 1998; 101: 952-3. 